\title{
Cardiovascular risk factors and mortality in children with chronic kidney disease
}

\author{
A Mudi, ${ }^{1,2}$ MBBS, FWACP, MSc (Med), Cert Nephrol (Paed); C Dickens, ${ }^{3}$ PhD; C Levy, ${ }^{1}$ MB BCh, FCPaed, MMed, Cert Nephrol (Paed); \\ D Ballot, ${ }^{1} \mathrm{MB}$ BCh, FCPaed, PhD \\ ${ }^{1}$ Department of Paediatrics and Child Health, Faculty of Health Sciences, University of the Witwatersrand, Johannesburg, South Africa \\ ${ }^{2}$ Department of Paediatrics, Bayero University, Kano, Nigeria \\ ${ }^{3}$ Department of Medicine, Faculty of Health Sciences, University of the Witwatersrand, Johannesburg, South Africa
}

Corresponding author: A Mudi (abdulmudi@gmail.com)

\begin{abstract}
Background. Cardiovascular disease (CVD) begins early in children with chronic kidney disease (CKD), and its progression is determined by the presence of single or multiple cardiovascular risk factors (CVRFs).

Objective. To determine the prevalence of CVRFs in children with CKD and their association with mortality in children on chronic dialysis. Methods. This comparative cross-sectional study recruited children aged 5 - 18 years with all stages of CKD. All patients had a short history taken along with a physical examination, and their blood samples were assessed for serum creatinine, urea, albumin, calcium, phosphorus, parathyroid hormone, alkaline phosphatase, total cholesterol (TC), haemoglobin and C-reactive protein. Urine samples were also assessed for proteinuria. Results. One hundred and six children who met the study criteria were recruited, 34 with CKD I, 36 with CKD II - IV and 36 with CKD $\mathrm{V}$ (dialysis). The overall median age was 11 years (range 8 - 14), and the male/female ratio was 2.1:1. The most common CVRF was anaemia (39.6\%). The rate of anaemia was higher in the dialysis group than in the CKD II - IV and CKD I groups (77.8\%, 33.3\% and 5.9\%, respectively). Other CVRFs detected were hypertension, proteinuria, hypercholesterolaemia and dysregulated mineral bone metabolism. Seven deaths were recorded in the dialysis group during the study period. Severe hypertension and intracranial bleeding were the most common causes of death. Modifiable risk factors such as increased TC and decreased albumin levels were more common than other CVRFs in the dialysis patients who died.

Conclusions. CVRFs may be present in early CKD, even before the decline in GFR. Routine screening for CVRFs, along with timely intervention, may prevent the progression of CVD and mortality later in life.
\end{abstract}

S Afr Med J 2017;107(8):710-714. DOI:10.7196/SAMJ.2017.v107i8.12271

Cardiovascular disease (CVD) is thought to begin early in chronic kidney disease (CKD) and to progress rapidly as renal function declines, especially on dialysis. ${ }^{[1-3]}$ CVD is the most common cause of death among paediatric patients with end-stage renal disease (ESRD). ${ }^{[4,5]}$

Traditional and non-traditional cardiovascular risk factors (CVRFs) play an important role in the initiation and progression of CVD in children with CKD. Combinations of these risk factors could cause accelerated manifestations of cardiac and vascular changes in children. ${ }^{[6,7]}$ Traditional CVRFs such as hypertension, dyslipidaemia, obesity and hyperglycaemia have been shown to be increased even in children with early stages of CKD. ${ }^{[3,6]}$ Nontraditional CVRFs including anaemia, fluid overload, dysregulated mineral bone metabolism (hyperparathyroidism, increased calciumphosphate product), hypoalbuminaemia, inflammation (increased C-reactive protein and cytokines) and oxidative stress are more evident in children with moderate to severe CKD. ${ }^{[1,5-9]}$ Other risk factors for CVD are potentially treatment related, such as calcium overload from dialysate, calcium-based phosphate binders and vitamin $\mathrm{D}$ therapy. ${ }^{[10-12]}$

In adults with ESRD, coronary artery disease and cardiomyopathy are the leading cause of CVD mortality. Children, however, die from cardiac arrest, arrhythmia, cardiomyopathy and, rarely, myocardial disease. ${ }^{[13,14]}$ Various vascular changes such as atherosclerosis, arteriosclerotic lesions (including fibrous or fibroelastic intimal thickening), disruption of the internal elastic lamella and atheromatous plaques have also been reported in children with
CKD. ${ }^{[6,8]}$ These vascular changes increase the risk of symptomatic CVD later in life. ${ }^{[7]}$

\section{Objective}

To investigate the prevalence of CVRFs and their association with mortality in children with CKD.

\section{Methods}

This comparative cross-sectional study recruited 106 children with CKD being followed up by the Division of Paediatric Nephrology at Charlotte Maxeke Johannesburg Academic Hospital and Chris Hani Baragwanath Academic Hospital, Johannesburg, South Africa (SA).

Thirty-four patients with CKD I, 36 with CKD II - IV and 36 with CKD V (dialysis) were recruited consecutively over a 12-month period (August 2015 - July 2016). The CKD I group were children with a glomerular filtration rate (GFR) of $>90 \mathrm{~mL} / \mathrm{min} / 1.73 \mathrm{~m}^{2}$ (with either structural abnormalities or isolated haematuria) with normal blood pressure and no proteinuria, the CKD II - IV group were those with GFR of $15-90 \mathrm{~mL} / \mathrm{min} / 1.73 \mathrm{~m}^{2}$, and the CKD V group were on maintenance haemodialysis and peritoneal dialysis.

Children with known congenital heart disease, diabetes mellitus, liver disease, active infection, systemic lupus erythematosus and malignancies and those who had had a renal transplant were excluded from the study.

All patients had a short demographic and clinical history taken along with a physical examination. Routine blood samples for serum creatinine, urea, albumin, calcium, phosphorus, parathyroid hormone 
(PTH), alkaline phosphatase (ALP), random total cholesterol (TC), haemoglobin and C-reactive protein (CRP) were taken, and results were retrieved and analysed.

\section{Definitions of terms}

- Hypertension. The need for antihypertensive treatment and/or according to the "Fourth report on the diagnosis, evaluation, and treatment of high blood pressure in children and adolescents. ${ }^{\text {[15] }}$

- Body mass index (BMI). Interpreted according to the World Health Organization (WHO) BMI centile for sex and age in children. ${ }^{[16]}$

- Proteinuria. Urine protein/creatinine ratio $>0.02 \mathrm{~g} / \mathrm{mmol}^{[17,18]}$

- Hypercholesterolaemia. Total cholesterol $>5.18 \mathrm{mmol} / \mathrm{L}$ ( $>200 \mathrm{mg} /$ dL). ${ }^{[19]}$

- Anaemia. Defined based on age according to the Kidney Disease Improving Global Outcome (KDIGO) clinical practice guidelines for anaemia in CKD. ${ }^{[20]}$

- Hyperphosphataemia, hypocalcaemia, hypercalcaemia, elevated calcium-phosphate product (CaXP) and elevated ALP. Defined based on age according to the Kidney Disease Outcomes Quality Initiative (KDOQI) clinical practice guidelines for bone metabolism and disease in children with CKD. ${ }^{[21]}$

- Hyperparathyroidism. PTH levels above the laboratory normal limit $(>7.6 \mathrm{pmol} / \mathrm{L})$ in pre-dialysis patients and above nine times the upper normal limit $(>68.4 \mathrm{pmol} / \mathrm{L})$ in dialysis patients, as recommended by KDIGO. ${ }^{[22]}$

- Hypoalbuminaemia. Serum albumin $<35 \mathrm{~g} / \mathrm{L} .{ }^{[23]}$

- Elevated CRP. CRP $>10 \mathrm{mg} / \mathrm{L} .{ }^{[24]}$

\section{Statistical analysis}

All data were collected and managed using Research Electronic Data Capture (REDCap) ${ }^{[25]}$ The computer-based statistical package Stata 13.1 (StataCorp, USA) was used for the analysis. Continuous variables were described using means and standard deviations for normally distributed data, and medians and interquartile ranges for skewed data. Categorical variables were presented as percentages and frequencies. Statistical significance in the prevalence of risk factors was tested for using $\chi^{2}$ tests or Fisher's exact tests, where appropriate. Mean/median values for the different groups were compared using analysis of variance, Kruskal-Wallis tests, $t$-tests and Mann-Whitney $U$-tests, depending on the distribution of the data. To compensate for multiple testing, Bonferroni-type correction was used to adjust for significant levels for the CVRFs as appropriate. Logistic regression analysis was used to determine the relationship between mortality and CVRFs. All CVRFs were tested using univariate logistic regression analysis, and only significant CVRFs $(p<0.05)$ are presented in Table 3 and included in the multivariate regression model. A confidence interval of $95 \%$ was used, and $p<0.05$ was regarded as significant.

\section{Ethics and approval}

The study was approved by the University of the Witwatersrand Human Research Ethics Committee (ref. no. M150312) and was conducted in compliance with the Helsinki Declaration, Good Clinical Practice and the laws and regulations of SA. Informed written consent/assent was obtained from participants where appropriate.

\section{Results}

The overall median age of the patients was 11 years (range 8 - 14), and the male/female ratio was 2.1:1 (Table 1).

Congenital anomalies of the kidneys and urinary tract were the most common cause of CKD across all groups, with a total rate of $47.2 \%(50 / 106)$ observed (Table 1$)$.
A breakdown of the nutritional status of the different groups of patients is illustrated in Fig. 1. The majority of the patients (79/106, $74.8 \%)$ were well nourished. Undernutrition was seen only in the dialysis group $(6 / 36,5.6 \%)$. Seventeen $(16.0 \%)$ of the patients were classified as overweight (10 CKD I, 7 CKD II - IV) and $3(2.8 \%)$ as being obese (1 CKD I, 1 CKD II - IV, 1 CKD V).

Anaemia (42/106, 39.6\%) was the most common CVRF, as shown in Table 1. Furthermore, anaemia differed significantly between the groups and was observed in 2/34 (5.9\%) patients with CKD I, 9/36 (25.0\%) of those with CKD II - IV and 31/36 (86.1\%) of those with CKD V $(p<0.001)$. Hypertension was the second most common CVRF, with a significantly higher rate in the dialysis group than in the CKD II - IV group (28/36 v. 12/36; $p<0.001)$. Elevated CaXP was the CVRF with the overall lowest rate $(6.5 \%)$ and was found in the dialysis group only. Similar trends were observed when the absolute values of the various CVRFs were compared across the groups (Table 1). The majority of these CVRFs remained significant after Bonferroni correction, where $p<0.004$ was considered significant (Table 1).

Over the 12-month duration of the study, we recorded seven deaths, all in the dialysis (CKD V) group. Cerebrovascular accident (intracranial bleed) associated with severe hypertension accounted for the majority $(4 / 7,57.1 \%)$ of the deaths (Fig. 2). Further analysis of the dialysis group showed a statistically significant difference in the presence of hypercholesterolaemia and hypoalbuminaemia

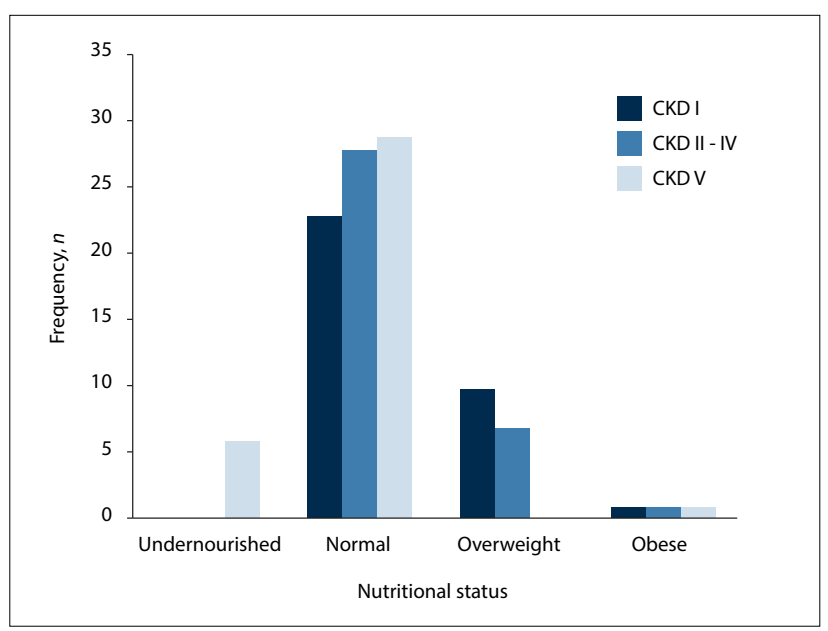

Fig. 1. Nutritional status of the study group. (CKD = chronic kidney disease. $)$

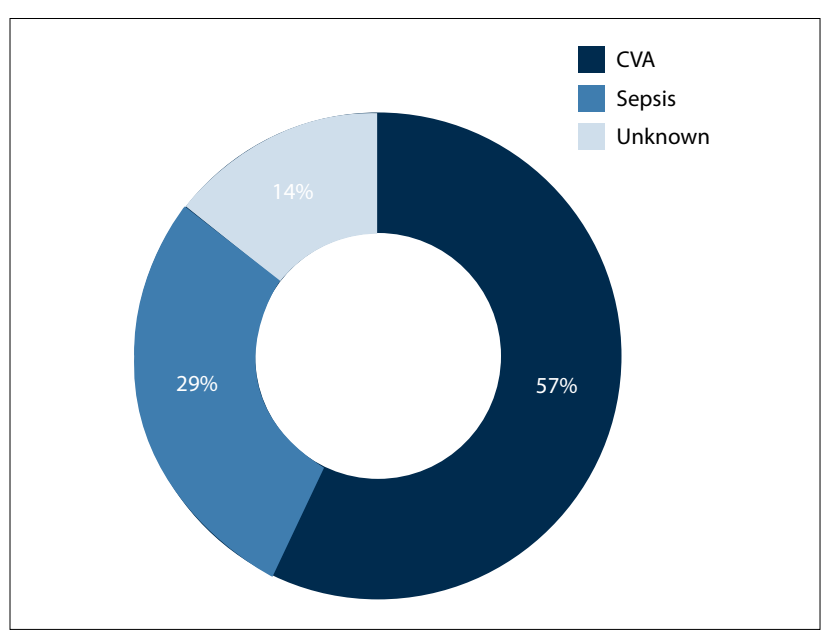

Fig. 2. Causes of death. (CVA = cerebrovascular accident. $)$ 
Table 1. Cardiovascular risk factors in all CKD patients

\begin{tabular}{|c|c|c|c|c|}
\hline & $\begin{array}{l}\text { CKD I } \\
(N=34) \\
\end{array}$ & $\begin{array}{l}\text { CKD II - IV } \\
(N=36)\end{array}$ & $\begin{array}{l}\text { CKD V (dialysis) } \\
(N=36)\end{array}$ & $p$-value \\
\hline Age (yr), mean (SD) & $9.48(2.85)$ & $11.28(3.52)$ & $11.86(3.77)$ & $0.012^{*}$ \\
\hline $\operatorname{Sex}(M / F)$ & $25: 9$ & $26: 10$ & $21: 15$ & 0.314 \\
\hline Diagnosis, $n(\%)$ & & & & 0.515 \\
\hline CAKUT & $13(38.2)$ & $19(52.8)$ & $18(50.0)$ & \\
\hline Glomerular disease & $12(35.3)$ & $13(36.1)$ & $11(30.6)$ & \\
\hline Others & $9(26.5)$ & $4(11.1)$ & $7(19.4)$ & \\
\hline MAP (mmHg), median (IQR) & $71(70-80)$ & $80(70-86)$ & $91(81-102)$ & $<0.001^{\star *}$ \\
\hline Hypertension, $n(\%)$ & 0 & $12(33.3)$ & $28(77.8)$ & $<0.001^{* *}$ \\
\hline BMI $\left(\mathrm{kg} / \mathrm{m}^{2}\right)$, median (IQR) & $17(15-18)$ & $18(16-19)$ & $16(15-18)$ & 0.089 \\
\hline Increased BMI, $n(\%)$ & $11(32.4)$ & $8(22.2)$ & $1(2.8)$ & $0.002^{\star *}$ \\
\hline $\mathrm{Hb}(\mathrm{g} / \mathrm{dL})$, median (IQR) & $13.2(12.5-14.4)$ & $13.4(12.1-14.3)$ & $9.3(8.1-10.6)$ & $<0.001^{* *}$ \\
\hline Anaemia, $n(\%)$ & $2(5.9)$ & $9(25.0)$ & $31(86.1)$ & $<0.001^{\star \star}$ \\
\hline CRP (mg/L), median (range) & $10^{\dagger}$ & $10(10-61)$ & $10(10-62)$ & $0.003^{* *}$ \\
\hline Increased CRP, $n(\%)$ & 0 & $4(11.1)$ & $10(27.8)$ & $0.002^{* *}$ \\
\hline TC (mmol/L), median (IQR) & $3.7(3.2-4.3)$ & $4.2(3.3-4.7)$ & $4.2(3.3-5.7)$ & 0.242 \\
\hline Hypercholesterolaemia, $n$ (\%) & $4(11.8)$ & $3(8.3)$ & $13(36.1)$ & $0.007^{\star}$ \\
\hline Albumin (mg/dl), median (IQR) & $44(42-45)$ & $44(41-45)$ & $36(30-39)$ & $<0.001^{* *}$ \\
\hline Hypoalbuminaemia, $n(\%)$ & 0 & $2(5.6)$ & $15(41.7)$ & $<0.001^{* *}$ \\
\hline Phosphate $(\mathrm{mmol} / \mathrm{L})$, mean $(\mathrm{SD})$ & $1.46(0.23)$ & $1.37(0.29)$ & $1.64(0.52)$ & $0.014^{\star}$ \\
\hline Hyperphosphataemia, $n(\%)$ & $4(11.8)$ & $4(11.1)$ & $17(47.2)$ & $<0.001^{\star *}$ \\
\hline CaXP, median (IQR) & $3.3(3.0-3.6)$ & $3.3(2.8-3.6)$ & $3.5(2.5-4.2)$ & 0.329 \\
\hline Increased CaXP, $n(\%)$ & 0 & 0 & $7(19.4)$ & $\neq$ \\
\hline ALP (U/L), median (IQR) & $245(212-328)$ & $263(184-313)$ & $250(184-484)$ & 0.773 \\
\hline Increased ALP, $n(\%)$ & $4(11.8)$ & $9(25.0)$ & $19(52.8)$ & $0.001^{\star *}$ \\
\hline PTH (pmol/L), median (IQR) & $3.5(2.7-5.3)$ & $6.6(4.0-10.9)$ & $77.9(17.4-144.5)$ & $<0.001^{\star *}$ \\
\hline Increased PTH & $4 / 34(11.8)$ & $15 / 35(42.9)$ & $19 / 36(52.8)$ & $0.001^{\star *}$ \\
\hline PCR (g/mmol), median (IQR) & $0.004(0.001-0.007)$ & $0.030(0.007-0.084)$ & $0.235(0.050-0.930)$ & $<0.001^{\star *}$ \\
\hline Proteinuria & 0 & $20 / 32(62.5)$ & $8 / 10(80.0)$ & $<0.001^{\star *}$ \\
\hline
\end{tabular}

between the patients who died and those who survived (Table 2). Similarly, the patients who died had significantly higher mean levels of TC and lower mean levels of albumin when compared with those who survived (Table 2). After Bonferroni correction, where $p<0.004$ was considered significant, only cholesterol remained significant (Table 2). Cholesterol and albumin levels were not associated with proteinuria in this subgroup. Univariate logistic regression analysis in the dialysis group showed an association of mortality with age, serum TC and albumin (Table 3). After adjusting for these three in a regression model, we found age to be the most important factor associated with mortality in our group of patients (Table 3 ).

\section{Discussion}

The initiation and progression of CVD in children with CKD are determined by the presence of single or multiple CVRFs, and CVD is thought to begin early and then worsen as renal function declines. Our study looked at traditional and non-traditional risk factors for CVD, as well as their association with mortality, in children with CKD.

The use of the BMI alone in determining the nutritional status of CKD patients on dialysis may not be appropriate because of interdialytic weight gain and variable dry-weight status. ${ }^{[26]}$ Despite these concerns, undernutrition was exclusively seen in the dialysis group and we recorded only a single case of overnutrition in the same group. A similar finding of undernutrition in advanced CKD has been reported in several studies. ${ }^{[27,28]}$ The finding of undernutrition in advanced CKD may be explained by low appetite, nausea and vomiting, and the effect of enforced dietary restriction resulting in caloric deficiency, along with chronic illness, an increased metabolic rate, metabolic acidosis and chronic inflammation, in a growing child. ${ }^{[29]}$

Being overweight or obese has been reported to increase the risk of having other CVRFs (hypertension, dyslipidaemia and abnormal glucose metabolism) when compared with lean patients. ${ }^{[3]}$ It should be emphasised at this point that the CKD I group did not have proteinuria, so it is unlikely that the presence of patients with nephrotic syndrome influenced the rate of hypercholesterolaemia in this group. In our study, overnutrition was most common in the CKD I and CKD II - IV groups, and we consider that this is a more likely explanation for the higher rate of hypercholesterolaemia in the CKD I group than in the CKD II - IV group.

Even though hypertension has been reported to be the single most important CVRF in CKD, ${ }^{[6,30,31]}$ we found anaemia to be the most common CVRF overall in our study, and hypertension to be the second most common overall. The high rate of anaemia probably reflects the undernutrition reported in the dialysis group, in addition to other causes of anaemia in CKD such as declining production of erythropoietin, inflammation, severe secondary hyperparathyroidism 
Table 2. Mortality and cardiovascular risk factors among dialysis patients

\begin{tabular}{|c|c|c|c|}
\hline & \multicolumn{3}{|c|}{ Mortality } \\
\hline & Yes $(N=7)$ & No $(N=29)$ & $p$-value \\
\hline Age (yr), mean (SD) & $7.71(2.81)$ & $12.86(3.28)$ & $0.005^{\star}$ \\
\hline Duration of dialysis (mo), mean (SD) & $11.43(9.20)$ & $25.72(36.50)$ & 0.309 \\
\hline BMI $\left(\mathrm{kg} / \mathrm{m}^{2}\right)$, median $(\mathrm{IQR})$ & $15(14-16)$ & $17(15-18)$ & $0.031^{\star}$ \\
\hline MAP (mmHg), mean (SD) & $85.86(16.69)$ & $93.66(18.61)$ & 0.435 \\
\hline Hypertension, $n(\%)$ & $5(71.4)$ & $23(79.3)$ & 0.639 \\
\hline $\mathrm{Hb}(\mathrm{g} / \mathrm{dL})$, mean $(\mathrm{SD})$ & $8.30(2.65)$ & $9.46(1.96)$ & 0.200 \\
\hline Anaemia, $n(\%)$ & $6(85.7)$ & $25(86.2)$ & 1.000 \\
\hline CRP (mg/L), median (IQR) & $10(10-29)$ & $10(10-14)$ & 0.441 \\
\hline Increased CRP, $n(\%)$ & $2(28.6)$ & $8(27.6)$ & 1.000 \\
\hline TC $(\mathrm{mmol} / \mathrm{L})$, mean $(\mathrm{SD})$ & $6.17(1.44)$ & $4.13(1.29)$ & $0.001^{* *}$ \\
\hline Hypercholesterolaemia, $n$ (\%) & $6(85.7)$ & $7(24.1)$ & $0.005^{*}$ \\
\hline Albumin (g/L), mean (SD) & $29.57(4.50)$ & $36.04(5.62)$ & $0.008^{*}$ \\
\hline Hypoalbuminaemia, $n(\%)$ & $6(85.7)$ & $9(31.0)$ & $0.013^{*}$ \\
\hline Phosphate (mmol/L), mean (SD) & $1.57(0.52)$ & $1.66(0.53)$ & 0.695 \\
\hline Hyperphosphataemia, $n$ (\%) & $3(42.9)$ & $14(48.3)$ & 1.000 \\
\hline CaXP, mean $(\mathrm{SD})$ & $3.31(1.26)$ & $3.59(1.37)$ & 0.622 \\
\hline Increased CaXP, $n(\%)$ & $1(14.3)$ & $6(20.7)$ & 1.000 \\
\hline PTH (pmol/L), mean (SD) & $71.49(69.42)$ & $89.19(74.36)$ & 0.571 \\
\hline Increased PTH, $n(\%)$ & $3(42.9)$ & $15(51.7)$ & 1.000 \\
\hline PCR (g/mmol), median (IQR) & $1.46(1.00-1.91)$ & $0.11(0.03-0.35)$ & 0.116 \\
\hline Proteinuria $^{\dagger}$ & $2 / 2$ & $6 / 8$ & 0.622 \\
\hline
\end{tabular}

Table 3. Logistic regression analysis for mortality among dialysis patients

\begin{tabular}{|c|c|c|c|c|c|c|}
\hline & \multicolumn{3}{|c|}{ Univariate } & \multicolumn{3}{|c|}{ Multivariate } \\
\hline & OR & $p$-value & 95\% CI & OR & $p$-value & 95\% CI \\
\hline Age (yr) & 0.62 & 0.008 & $0.44-0.88$ & 0.67 & 0.058 & $0.44-1.01$ \\
\hline $\mathrm{TC}(\mathrm{mmol} / \mathrm{L})$ & 2.83 & 0.008 & $1.31-6.14$ & 2.32 & 0.119 & $0.81-6.68$ \\
\hline Albumin (mg/dL) & 0.81 & 0.021 & $0.68-0.97$ & 0.85 & 0.194 & $0.66-1.09$ \\
\hline
\end{tabular}

leading to myelofibrosis, bone marrow hyporesponsiveness and infection. ${ }^{[32]}$ In spite of anaemia being a modifiable risk that can be corrected with erythropoiesis-stimulating agents and iron supplements, poor absorption of oral iron and poor compliance with oral iron due to side-effects such as constipation, diarrhoea and abdominal discomfort may have also contributed to the high rate of anaemia in our patients.

Across the study groups, except for overnutrition, the rates of recorded CVRF were highest in the dialysis group. Previous studies have documented a similar pattern in children with CKD..$^{[6,33,34]}$

Although less common, increased serum TC, phosphate, ALP, PTH and anaemia were also seen in the CKD I group. This may be attributed to the presence of early changes of CKD even before a decline in GFR, onset of proteinuria and hypertension are manifest.

The high death rate recorded over the study period is concerning, with severe hypertension and cerebrovascular accident (intracranial bleed) accounting for most deaths. Our observations differ from the cardiac-related deaths reported in other cohorts of paediatric CKD patients on dialysis, ${ }^{[13,14]}$ where cardiac arrest, arrhythmia, cardiomyopathy, cardiac failure and myocardial infarction/ischaemia were the most common causes of death. This difference may be attributed to lack of adequate volume and blood pressure control in our dialysis group, leading to severe hypertension. Our findings further emphasise the need for adequate blood pressure and fluid volume control in our chronic dialysis patients, in addition to control of other CVRFs.

Younger age at commencement of dialysis, especially age $<1$ year, has been associated with poorer survival compared with patients who are older ( $>5$ years) at the start of dialysis. ${ }^{[13,14]}$ Similarly, we found age to be a factor associated with mortality in our group of patients.

The finding of a higher rate of increased TC and decreased albumin levels in the dialysis patients who died may be indicative of their role in mortality. Even though neither TC nor albumin levels were significantly associated with mortality after adjusting for age in this study, it is nevertheless still important to correct TC and albumin levels in all patients with $\mathrm{CKD}$, as previous studies have implicated both of these risk factors as predictors of morbidity and mortality in CKD. ${ }^{[23,35-37]}$

\section{Study strengths and limitations}

This is the first African study to look at traditional and nontraditional risk factors for CVD, as well as their association with mortality, among children with CKD. The major limitation is the small number of patients in this study and the lack of a disease-free 
control group for comparison. Another limitation is that random and not fasting cholesterol was measured.

\section{Conclusions}

CVRFs may be present in early CKD, even before the decline in GFR is detected, and tend to worsen as renal function deteriorates, especially in patients on dialysis. These risk factors play an important role in the morbidity and mortality associated with CVD in children with CKD. Routine screening for these CVRFs, along with timely intervention, may go a long way towards preventing the progression of CVD and cardiac-related mortality later in life.

Acknowledgements. The authors acknowledge the contribution of all the team members who provided care for these children and assisted with this study.

Author contributions. All the authors contributed to the manuscript significantly, reviewed it and approved its submission to the SAMJ.

Funding. Funding for this research was received from the Carnegie Corporation, New York, the Iris Ellen Hodges Cardiovascular Research Trust, and the University of the Witwatersrand Faculty of Health Sciences Seed Funding for Research.

Conflicts of interest. None.

1. Thomas R, Kanso A, Sedor JR. Chronic kidney disease and its complications. Prim Care 2008;35(2):329344, vii. https:/doi.org/10.1016/j.pop.2008.01.008

2. Paoli S, Mitsnefes MM. Coronary artery calcification and cardiovascular disease in children with chronic kidney disease. Curr Opin Pediatr 2014;26(2):193-197. https:/doi.org/10.1097/MOP.0000000000000059

3. Wilson AC, Schneider MF, Cox C, et al. Prevalence and correlates of multiple cardiovascular risk factors in children with chronic kidney disease. Clin J Am Soc Nephrol 2011;6(12):2759-2765. https:/doi. org/10.2215/CJN.03010311

4. Chavers BM, Molony JT, Solid CA, Rheault MN, Collins AJ. One-year mortality rates in US children with end-stage renal disease. Am J Nephrol 2015;41(2):121-128. https:/doi.org/10.1159/000380828 5. Mitsnefes MM. Cardiovascular disease in children with chronic kidney disease. J Am Soc Nephrol
2012;23(4):578-585. https:/doi.org/10.1681/ASN.2011111115

6. Wong CJ, Moxey-Mims M, Jerry-Fluker J, Warady BA, Furth SL. CKiD (CKD in children) prospective cohort study: A review of current findings. Am J Kidney Dis 2012;60(6):1002-1011. https:/doi.
cons org $10.1053 /$ jajkd 2012.07 .018

7. Wilson AC, Mitsnefes MM. Cardiovascular disease in CKD in children: Update on risk factors, risk assessment, and management. Am J Kidney Dis 2009;54(2):345-360. https:/doi.org/10.1053/j. ajkd.2009.04.02

8. Shroff R, Long DA, Shanahan C. Mechanistic insights into vascular calcification in CKD. J Am Soc Nephrol 2013;24(2):179-189. https:/doi.org/10.1681/ASN.2011121191

9. Fischbach M, Zaloszyc A, Shroff R. The interdialytic weight gain: A simple marker of left ventricular hypertrophy in children on chronic haemodialysis. Pediatr Nephrol 2015;30(6):859-863. https:/doi. org/10.1007/s00467-015-3086-6

10. Shroff R, Egerton M, Bridel M, et al. A bimodal association of vitamin D levels and vascular disease in children on dialysis. J Am Soc Nephrol 2008;19(6):1239-1246. https:/doi.org/10.1681/ASN.2007090993

11. Mitsnefes MM, Kimball TR, Kartal J, et al. Cardiac and vascular adaptation in pediatric patients with chronic kidney disease: Role of calcium-phosphorus metabolism. J Am Soc Nephrol 2005;16(9):27962803. https:/doi.org/10.1681/ASN.2005030291

12. Civilibal M, Caliskan S, Adaletli I, et al. Coronary artery calcifications in children with end-stage renal disease. Pediatr Nephrol 2006;21(10):1426-1433. https:/doi.org/10.1007/s00467-006-0159-6
13. Mitsnefes MM, Laskin BL, Dahhou M, Zhang X, Foster BJ. Mortality risk among children initially treated with dialysis for end-stage kidney disease, 1990 - 2010. JAMA 2013;309(18):1921-1929. https: doi.org/10.1001/jama.2013.4208

14. Samuel SM, Tonelli MA, Foster BJ, et al. Survival in pediatric dialysis and transplant patients. Clin J Am Soc Nephrol 2011;6(5):1094-1099. https:/doi.org/10.2215/CJN.04920610

15. National High Blood Pressure Education Program Working Group on High Blood Pressure in Children ational High Blood Pressure Education Program Working Group on High Blood Pressure in Children
and Adolescents. The fourth report on the diagnosis, evaluation and treatment of high blood pressure in children and adolescents. Pediatrics 2004;114(Suppl 2):555-576.

16. De Onis M, Onyango AW, Borghi E, Siyam A, Nishida C, Siekmann J. Development of a WHO growth reference for school-aged children and adolescents. Bull World Health Organ 2007;85(9):660-667. https: doi.org/10.2471/BLT.07.043497

17. Agarwal I, Kirubakaran C, Markandeyulu, Selvakumar. Quantitation of proteinuria by spot urine sampling. Indian J Clin Biochem 2004;19(2):45-47. https:/doi.org/10.1007/BF02894256

18. Loghman-Adham M. Evaluating proteinuria in children. Am Fam Physician 1998;58(5):1145-1152 1158-1149.

19. Saland JM, Pierce CB, Mitsnefes MM, et al. Dyslipidemia in children with chronic kidney disease. Kidney Int 2010;78(11):1154-1163. https:/doi.org/10.1038/ki.2010.311

20. Kidney Disease Improving Global Outcome (KDIGO). Clinical practice guideline for anemia in chronic kidney disease. Kidney Int Suppl 2012;2(4):279-335.

21. Kidney Disease Outcomes Quality Initiative (KDOQI). Clinical practice guidelines for bone metabolism and disease in children with chronic kidney disease. Am J Kidney Dis 2005;46(4, Suppl 1):S1-S103.

22. Kidney Disease Improving Global Outcome (KDIGO). Clinical practice guideline for the diagnosis, Kidney Disease Improving Global Outcome (KDIGO). Clinical practice guideline for the diagnosis,
evaluation, prevention, and treatment of chronic kidney disease-mineral and bone disorder (CKDevaluation, prevention, and treatment of chron
MBD). Kidney Int 2009;76(Suppl 113):S3-S130.

23. Wong CS, Hingorani S, Gillen DL, et al. Hypoalbuminemia and risk of death in pediatric patients with end-stage renal disease. Kidney Int 2002;61 (2):630-637. https:/doi.org/10.1046/j.1523-1755.2002.00169.X

24. McIntyre C, Harper I, Macdougall IC, Raine AE, Williams A, Baker LR. Serum C-reactive protein as marker for infection and inflammation in regular dialysis patients. Clin Nephrol 1997;48(6):371-374.

25. Harris PA, Taylor R, Thielke R, Payne J, Gonzalez N, Conde JG. Research electronic data capture (REDCap) - a metadata-driven methodology and workflow process for providing translational research informatics support. J Biomed Inform 2009;42(2):377-381. https:/doi.org/10.1016/j.jbi.2008.08.010

26. Foster BJ, Leonard MB. Measuring nutritional status in children with chronic kidney disease. Am J Clin Nutr 2004;80(4):801-814.

27. Apostolou A, Printza N, Karagiozoglou-Lampoudi T, Dotis J, Papachristou F. Nutrition assessment of children with advanced stages of chronic kidney disease - a single center study. Hippokratia 2014;18(3):212-216

28. Gupta A, Mantan M, Sethi M. Nutritional assessment in children with chronic kidney disease. Saudi J Kidney Dis Transpl 2016:27(4):733-739. https:/doi.org/10.4103/1319-2442.185235 29. Mastrangelo A, Paglialonga F, Edefonti A. Assessment of nutritional status in children with chronic
kidney disease and on dialysis. Pediatr Nephrol 2014;29(8):1349-1358. https:/doi.org/10.1007/s00467kidney disease
$013-2612-7$

30. Kupferman JC, Aronson Friedman L, Cox C, et al. BP control and left ventricular hypertrophy regression in children with CKD. J Am Soc Nephrol 2014;25(1):167-174. https:/doi.org/10.1681/ASN.2012121197

31. Mitsnefes M, Flynn J, Cohn S, et al. Masked hypertension associates with left ventricular hypertroph in children with CKD. J Am Soc Nephrol 2010;21(1):137-144. https:/doi.org/10.1681/ASN.2009060609

32. Koshy SM, Geary DF. Anemia in children with chronic kidney disease. Pediatr Nephrol 2008;23(2):209219. https:/doi.org/10.1007/s00467-006-0381-2

33. Rinat C, Becker-Cohen R, Nir A, et al. A comprehensive study of cardiovascular risk factors, cardiac function and vascular disease in children with chronic renal failure. Nephrol Dial Transplant 2010;25(3):785-793. https:/doi.org/10.1093/ndt/gfp570

34. Fadrowski JJ, Pierce CB, Cole SR, Moxey-Mims M, Warady BA, Furth SL. Hemoglobin decline in children with chronic kidney disease: Baseline results from the Chronic Kidney Disease in Children Prospective Cohort Study. Clin J Am Soc Nephrol 2008;3(2):457-462. https:/doi.org/10.2215/CJN.03020707

35. Berenson GS, Srinivasan SR, Bao W, Newman WP 3rd, Tracy RE, Wattigney WA. Association between Berenson GS, Srinivasan SR, Bao W, Newman WP 3rd, Tracy RE, Wattigney WA. Association between
multiple cardiovascular risk factors and atherosclerosis in children and young adults: The Bogalusa Heart Study. N Engl J Med 1998;338(23):1650-1656. https:/doi.org/10.1056/NEJM199806043382302

36. Shah NR, Dumler F. Hypoalbuminaemia - a marker of cardiovascular disease in patients with chronic kidney disease stages II - IV. Int J Med Sci 2008;5(6):366-370.

37. Owen WF Jr, Lew NL, Liu Y, Lowrie EG, Lazarus JM. The urea reduction ratio and serum albumin concentration as predictors of mortality in patients undergoing hemodialysis. N Engl J Med 1993;329(14):1001-1006. https:/doi.org/10.1056/NEJM199309303291404

Accepted 18 April 2017. 